\title{
Radiographic comparison between male and female patients with lumbar spondylolysis
}

\author{
Shoichiro Takao', Toshinori Sakai', Koichi Sairyo², Tadashi Kondo ${ }^{3}$ Junji Ueno', \\ Natsuo Yasui ${ }^{2}$, and Hiromu Nishitani ${ }^{4}$ \\ ${ }^{1}$ Department of Radiologic Science and Technology, ${ }^{2}$ Department of Orthopedics, ${ }^{3}$ Department of Medi- \\ cal Imaging Informatics, and ${ }^{4}$ Department of Radiology, Institute of Health Biosciences, the University \\ of Tokushima Graduate School, Tokushima, Japan
}

\begin{abstract}
We studied the lumbar spines of 117 adults (39 women and 78 men) with spondylolysis unrelated to low back pain using multidetector computed tomography (CT). Of the 117 subjects with spondylolysis, including five with multiple-level spondylolysis, there were 124 vertebrae with spondylolysis. In adult lumbar spines with unilateral spondylolysis, there was no significant difference between the incidence of spondylolisthesis in female and male subjects. However, in those with bilateral spondylolysis, there was a significantly higher incidence of spondylolisthesis in female subjects $(90.9 \%)$ than in males (66.2\%). Furthermore, females with bilateral spondylolysis had significant more slippage than males. Lumbar index and lumbar lordosis were not significantly different between male and female subjects, and did not significantly correlate with slippage. In conclusion, to treat acute spondylolysis in adolescents, it is important to obtain bony union at least unilaterally, especially in female subjects, to prevent further slippage. J. Med. Invest. 57 : 133-137, February, 2010
\end{abstract}

Keywords : spondylolysis, computed tomography, spondylolisthesis, gender differences, lumbar spines

\section{INTRODUCTION}

Spondylolysis is thought to be a stress fracture of the pars interarticularis that occurs frequently in adolescent sports players $(1,2)$. Some patients with spondylolysis concomitantly have various deformities of the lumbosacral region, including slippage of the vertebral body (spondylolisthesis) and/or wedging deformity $(1,3-10)$. Saraste reported that approximately $80 \%$ of patients with spondylolysis showed slippage, and in one-fifth of these patients the slippage exceeded 25\% (11). Wedging deformity

Received for publication November 26, 2009 ; accepted January $12,2010$.

Address correspondence and reprint requests to Hiromu Nishitani, MD, PhD, Department of Radiology, Institute of Health Biosciences the University of Tokushima Graduate School, 3-1815 Kuramoto-cho, Tokushima 770-8503, Japan and Fax : +81886-7174 of the spondylolytic vertebra has been interpreted as an expression of the hypoplastic dysplasia and commonly accepted as the cause of spondylolysis and spondylolisthesis. Sairyo et al. examined 46 adolescent athletes with symptomatic spondylolysis and reported that slippage at L5 was correlated with the maturity of the lumbar spine : slippage occurred in the immature spine and ceased when the vertebra matured. Furthermore, they suggested that the wedge deformity of the affected vertebra might be a result rather than a cause of slippage (12).

There have been reports that adolescent females have a higher degree of slippage at diagnosis than adolescent males $(9,13)$. There have been no reports of gender differences of these deformities associated with spondylolysis in the general population. Here, we studied the lumbar spine in adults with spondylolysis unrelated to low back pain using 
multidetector computed tomography (CT), and focused on gender differences.

\section{MATERIALS AND METHODS}

\section{Subjects}

A total of 117 patients (39 women and 78 men) with lumbar spondylolysis were included in this study. Mean patient age was 63.0 (22 to 87) years. All patients also participated in our preliminary study (14). Patients underwent abdominal and pelvic CT with a single multidetector $\mathrm{CT}$ scanner for reasons unrelated to lower back pain. All CT scans were ordered from the departments of general surgery and gynecology. Each CT was performed using a 16-detector-row CT scanner (Aquilion 16 ; Toshiba Medical Systems, Tokyo, Japan) with a rotation time of $0.5 \mathrm{~s}$, helical pitch 15 (beam pitch 0.9375), tube voltage $120 \mathrm{kV}$, and tube current 10-400 mA (SD 8.5). The acquired images were reconstructed into CT images (thickness $1 \mathrm{~mm}$ ) utilizing the CT image reconstruction function of FC10 or FC 50. Observation was performed using a 1-mm slice thickness MPR (multi planer reconstruction) image with Aquarius NET Server (TeraRecon, Inc ; San Mateo, CA, USA) under standard bone settings (window width 2200 , window level 200). S.T. (certified radiologist) and T.S. (certified spine surgeon) reviewed all images, and diagnosis and measurements were achieved by consensus. An institutional review board exemption was obtained for reviewing the imaging studies along with the indications for the studies and the official CT reports.

\section{Measurements}

In the previous studies, measurements have been made using plain X-ray films ; there have been no previously defined criteria for using CT images for these measurements. We measured degree of translation (mm), slippage (\%), lumbar index (\%), and lumbar lordosis (degrees), which are thought to be associated with spondylolysis. All measurements were performed using mid-sagittal and mid-coronal sections (Figure 1).

\section{Degree of slippage}

Measurements of degree (translation) of slippage were conducted on mid-sagittal view (Figure 2-a). Percent slippage was measured according to the method described by Wiltse and Winter (15).

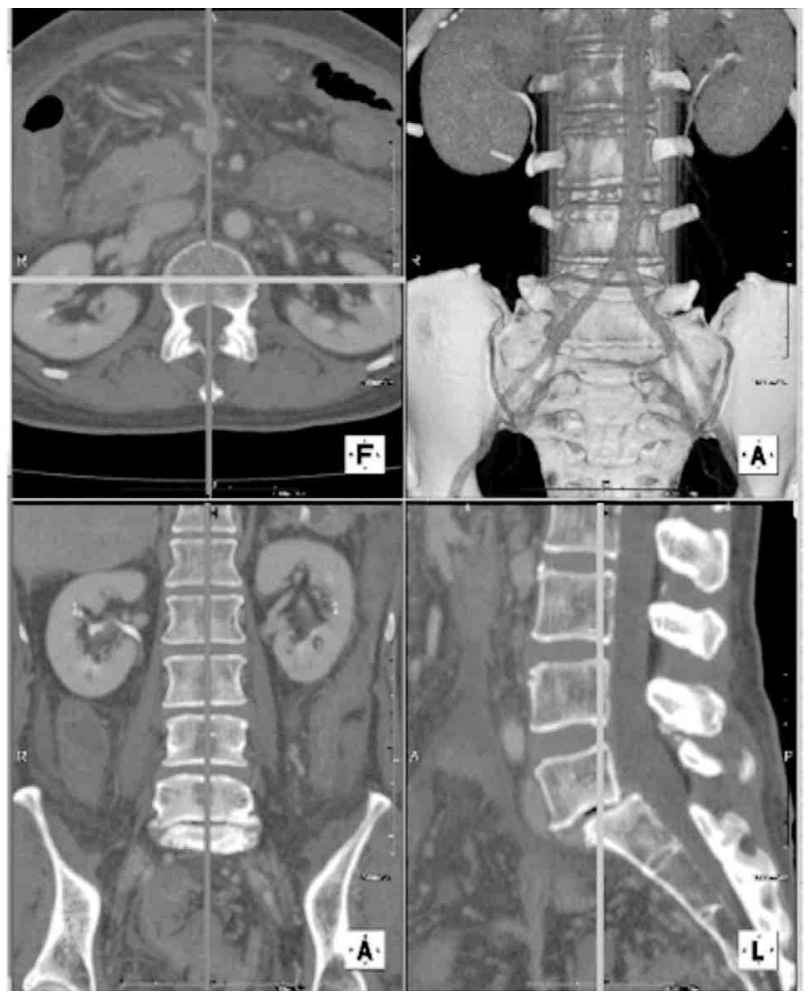

Figure 1. All measurements were performed using 1-mm slice thickness CT scans reconstructed with Aquarius NET Server, and using mid-sagittal and mid-coronal sections.

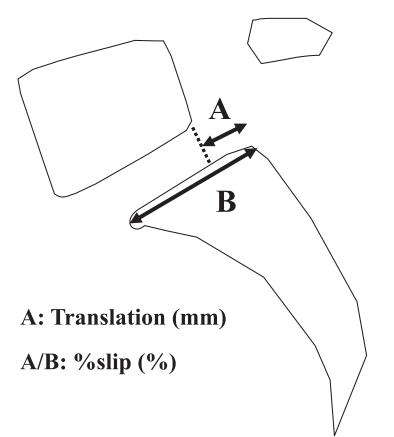

(a)

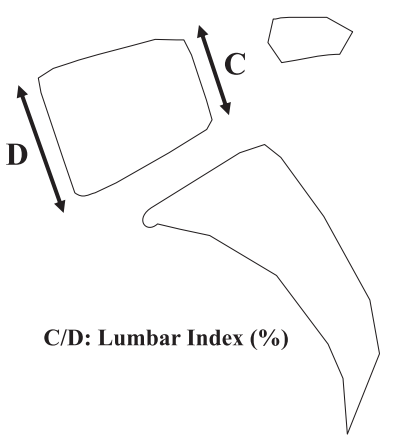

(b)
Figure 2. (a) Measurements of degree (translation) of slippage were conducted on mid-sagittal view. Percent slippage was measured according to the method described by Wiltse and Winter (15).

(b) Lumbar index was measured on mid-sagittal view.

\section{Lumbar index}

Lumbar index (LI) was measured on mid-sagittal view (Figure 2-b).

\section{Lumbar lordosis}

Lumbar lordosis was measured from the superior endplate of $\mathrm{L} 1$ to the superior endplate of S1 (Figure 3). 


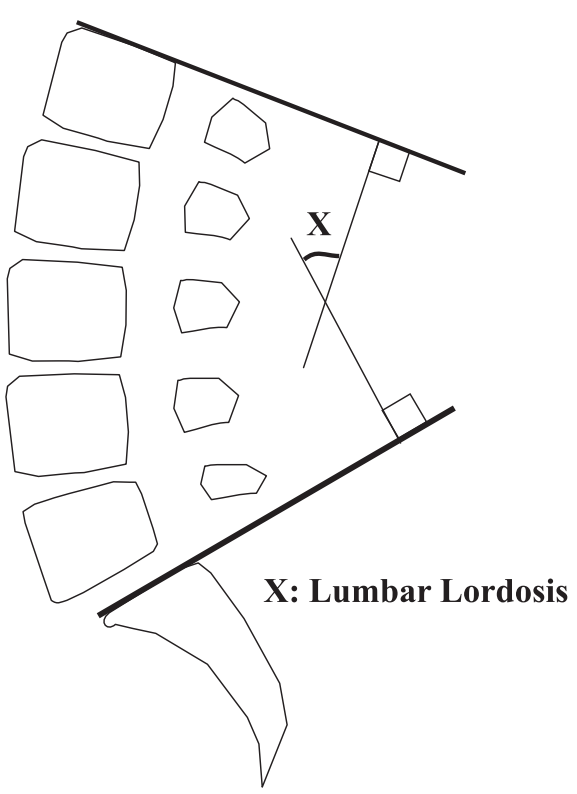

Figure 3. Lumbar lordosis was measured from the superior endplate of L1 to the superior endplate of S1.

\section{Statistical analysis}

The statistical analyses were performed using cross tabulation (Fisher's exact probability test), Mann-Whitney U test in comparisons of nonparametric variables, and Spearman's rank correlation coefficient test. The statistical difference was recognized as significant, when the $\mathrm{p}$ value was less than 0.01 .

\section{RESULTS}

In the 117 patients with spondylolysis, including five with multiple-level spondylolysis, there were 124 affected vertebrae. There were 26 vertebrae with unilateral spondylolysis and 98 vertebrae with bilateral spondylolysis.

Of the 26 subjects with unilateral spondylolysis, nine were female (mean age : 60.9 \pm 15.4 years, range : $37-83$ years) and 17 were male (mean age : $67.4 \pm 14.4$ years, range : $22-87$ years). In the group of 17 males, there were two subjects (11.8\%) with slippage, whereas none $(0 \%)$ of the nine females had slippage. However, there was no statistically significant difference (Fisher's exact probability test) between these results (Table 1).

Table 1.

\begin{tabular}{ccc} 
Unilateral Spondylolysis & Men & Women \\
\hline Subjects with Slippage & $2(11.8 \%)$ & $0(0 \%)$ \\
Subjects without Slippage & $15(88.2 \%)$ & $9(100 \%)$ \\
\hline Total & 17 & 9
\end{tabular}

Of the 98 subjects with bilateral spondylolysis, there were 33 females (mean age : $61.4 \pm 12.2$ years, range : 35 -83 years) and 65 males (mean age: $63.1 \pm 14.4$ years, range : $24-87$ years). Of the 65 male subjects there were $43(66.2 \%)$ with slippage, whereas of the 33 female subjects there were 30 $(90.9 \%)$ with slippage. There was a statistically significant difference between the two groups ( $p<0.01$, Fisher's exact probability test) (Table 2).

Table 2.

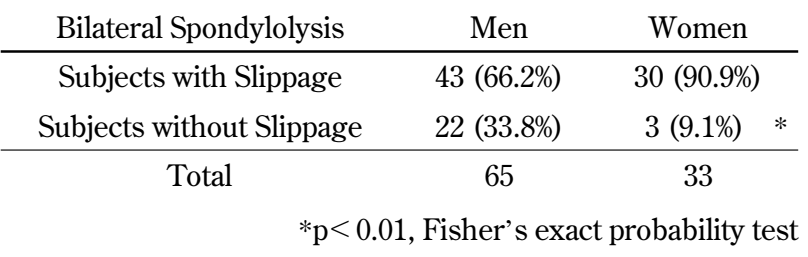

In subjects with unilateral spondylolysis, translation, percent slippage, lumbar index, and lumbar lordosis were not significantly different between male and female subjects (Table 3). Whereas in those with bilateral spondylolysis, translation and percent slippage were statistically significantly greater in females than in males $(\mathrm{p}<0.01$, Mann-Whitney $\mathrm{U}$ test) (Table 4).

In subjects with bilateral spondylolysis, there was no correlation between age and slippage (translation, percent slippage) (Spearman's rank correlation coefficient test) in either males or females. Additionally, there were no correlations between lumbar index or lumbar lordosis and slippage (translation, percent slippage).

Table 3.

$\underline{\text { Unilateral Spondylolysis : } 26 \text { Vertebrae }}$

\begin{tabular}{lccc} 
& Men $(\mathrm{n}=17)$ & Women $(\mathrm{n}=9)$ & \\
\hline Translation (mm) & $0.41 \pm 1.17$ & 0 & N. S. \\
Percent slippage (\%) & $1.26 \pm 3.45$ & 0 & N. S. \\
Lumbar Index (\%) & $83.32 \pm 6.72$ & $80.90 \pm 7.50$ & N. S. \\
Lumbar Lordosis (degree) & $52.23 \pm 8.23$ & $49.20 \pm 12.70$ & N. S. \\
\hline
\end{tabular}


Table 4.

\begin{tabular}{lccc} 
& \multicolumn{2}{c}{ Bilateral Spondylolysis : 98 Vertebrae } \\
& Men $(\mathrm{n}=65)$ & Women $(\mathrm{n}=33)$ & \\
\hline Translation (mm) & $4.06 \pm 3.41$ & $5.64 \pm 2.90$ & $*$ \\
Percent slippage (\%) & $11.42 \pm 9.65$ & $17.75 \pm 9.93$ & N. S. \\
Lumbar Index (\%) & $80.73 \pm 9.11$ & $79.30 \pm 8.58$ & N. S. \\
Lumbar Lordosis (degree) & $51.00 \pm 7.92$ & $52.07 \pm 10.17$ & \\
\hline
\end{tabular}

$* \mathrm{p}<0.01$, Mann-Whitney U test

\section{DISCUSSION}

In adult lumbar spines with unilateral spondylolysis, there was no significant difference between the incidence of spondylolisthesis in male (11.8\%) and female subjects $(0 \%)$. However, in those with bilateral spondylolysis, there was a significantly higher incidence of spondylolisthesis in females (90.9\%) than in males $(66.2 \%)$. Slippage in patients with spondylolysis is thought to be most prevalent during the growth period and rare thereafter $(8,13)$. Sairyo et al. retrospectively reviewed immature patients with spondylolysis to elucidate the relationship between the maturity of the lumbosacral spine and the development of slippage (12). They concluded that slippage was more prevalent in individuals of a younger skeletal age, whose lumbar spine was immature, and it ceased once the growth period was over and the vertebra had matured. From these results, it appears that to treat acute spondylolysis in adolescence it is important to obtain bony union at least unilaterally, especially in female subjects.

In the present study, female subjects with bilateral spondylolysis had significantly more slippage than males. This result was consistent with previous reports. It has previously been reported that girls have a greater degree of slippage at diagnosis $(13,16)$. Based on these results, we suggest that a young female patient with acute bilateral spondylolysis will have a predisposition to severe slippage. The etiology of this difference between males and females is unknown. Slippage of the lumbar spine with spondylolysis occurs between the osseous and cartilaginous end plates because the site including the growth plate is the weakest link to anterior shearing forces (17-20). Therefore, we speculate that there is a gender difference in the fragility of the growth plate.

Lumbar index (wedging deformity) and lumbar lordosis showed no significant difference between male and female subjects. Furthermore, they did not significantly correlate with slippage. Ikata et al. have reported that, in adolescents, wedging deformity was not evident if the pars defect was in the early stages of development but the degree of deformity increased as the stage of the pars defect advanced and as slippage developed (17). These results suggest that although the wedging deformity could correlate with slippage during the growth period, it does not affect the degree of slippage after maturation of the spine. There is controversy regarding possible correlation between lumbar lordosis and slippage (21-24) ; consistent with the present study, some reports have demonstrated no correlation $(23,24)$.

The main limitation of this study was that, as it is based on CT scans, slippage and lumbar lordosis were evaluated under static conditions. Therefore, dynamic changes in slippage by lumbar flexion/ extension were not evaluated, and lumbar lordosis was not measured in the standing position.

In conclusion, in subjects with bilateral spondylolysis, there was a significantly higher incidence of spondylolisthesis in female subjects than in males. Furthermore, female subjects with bilateral spondylolysis had significantly more slippage than males. Therefore, to treat acute spondylolysis in adolescents, it is important to obtain bony union at least unilaterally to prevent further slippage, especially in female subjects.

\section{REFERENCES}

1. Wiltse LL: The etiology of spondylolisthesis. J Bone Joint Surg Am 44 : 539-560, 1962

2. Sairyo K, Katoh S, Sakamaki T, Komatsubara $\mathrm{S}$, Endo K, Yasui $\mathrm{N}$ : Three successive stress fractures at the same level in an adolescent baseball player. Am J Sports Med 31 : 606-610, 2003

3. Wiltse LL, Newman PH, Macnab I : Classification of spondylolisis and spondylolisthesis. Clin 
Orthop Relat Res $117: 23-29,1976$

4.. Farfan HF, Osteria V, Lamy C : The mechanical etiology of spondylolysis and spondylolisthesis. Clin Orthop Relat Res 117 : 40-55, 1976

5. Krenz J, Troup JD : The structure of the pars interarticularis of the lower lumbar vertebrae and its relation to the etiology of spondylolysis, with a report of a healing fracture in the neural arch of a fourth lumbar vertebra. J Bone Joint Surg Br 55 : 735-741, 1973

6. Lafferty JF, Winter WG, Gambaro SA : Fatigue characteristics of posterior elements of vertebrae. J Bone Joint Surg Am 59 : 154-158, 1977

7. Morita T, Ikata T, Katoh S, Miyake R: Lumbar spondylolysis in children and adolescents. J Bone Joint Surg Br 77 : 620-625, 1995

8. Fredrickson BE, Baker D, McHolick WJ, Yuan HA, Lubicky JP : The natural history of spondylolysis and spondylolisthesis. J Bone Joint Surg Am 66 : 699-707, 1984

9. Boxall D, Bradford DS, Winter RB, Moe JH : Management of severe spondylolisthesis in children and adolescents. J Bone Joint Surg Am 61 : 479-495, 1979

10. Seitsalo S, Osterman K, Poussa M, Laurent LE : Spondylolisthesis in children under 12 years of age : long-term results of 56 patients treated conservatively or operatively. J Pediatr Orthop $8: 516-521,1988$

11. Saraste $\mathrm{H}:$ Spondylolysis and spondylolisthesis. Acta Orthop Scand (Suppl 251) : 84-86, 1993

12. Sairyo K, Katoh S, Ikata T, Fujii K, Kajiura K, Goel VK : Development of spondylolytic olisthesis in adolescents. Spine J $1: 171-175,2001$

13. Seitsalo S, Osterman K, Hyvãrinen $H$, Tallroth $\mathrm{K}$, Schlenzka D, Poussa M : Progression of spondylolisthesis in children and adolescents. A long-term follow-up of 272 patients. Spine (Phila Pa 1976) 1991 ; 16(4) : 417-21.

14. Sakai T, Sairyo K, Takao S, Nishitani H, Yasui $\mathrm{N}$ : Incidence of lumbar spondylolysis in the general population in Japan based on multidetector computed tomography scans from two thousand subjects. Spine (Phila Pa 1976) 34 : 2346-2350, 2009

15. Wiltse LL, Winter RB : Terminology and measurement of spondylolisthesis. J Bone Joint Surg
Am 65 : 768-772, 1983

16. Danielson BI, Frennered AK, Irstam LK : Radiologic progression of isthmic lumbar spondylolisthesis in young patients. Spine (Phila $\mathrm{Pa}$ 1976) 16(4) : 422-425, 1991

17. Ikata T, Miyake R, Katoh S, Morita T, Murase $\mathrm{M}$ : Pathogenesis of sports-related spondylolisthesis in adolescents. Radiographic and magnetic resonance imaging study. Am J Sports Med 24 : 94-98, 1996

18. Kajiura K, Katoh S, Sairyo K, Ikata T, Goel VK, Murakami RI : Slippage mechanism of pediatric spondylolysis : biomechanical study using immature calf spines. Spine (Phila Pa 1976) 26(20) : 2208-2212, 2001

19. Konz RJ, Goel VK, Grobler LJ, Grosland NM, Spratt KF, Scifert JL, Sairyo K: The pathomechanism of spondylolytic spondylolisthesis in immature primate lumbar spines in vitro and finite element assessments. Spine (Phila $\mathrm{Pa}$ 1976) 26(4) : E38-49, 2001

20. Sairyo K, Goel VK, Grobler LJ, Ikata T, Katoh $\mathrm{S}$ : The pathomechanism of isthmic lumbar spondylolisthesis. A biomechanical study in immature calf spines. Spine (Phila Pa 1976) 23 (13) : 1442-1446, 1998

21. Roussouly P, Gollogly S, Berthonnaud E, Labelle H, Weidenbaum M : Sagittal alignment of the spine and pelvis in the presence of L5-S1 isthmic lysis and low-grade spondylolisthesis. Spine (Phila Pa 1976) 31 : 2484-2490, 2006

22. Labelle H, Roussouly P, Berthonnaud E, Dimnet J, O'Brien $\mathrm{M}$ : The importance of spinopelvic balance in L5-S1 developmental spondylolisthesis : a review of pertinent radiologic measurements. Spine (Phila Pa 1976) 30 (6 Suppl) : S27-S34, 2005

23. Rajnics P, Templier A, Skalli W, Lavaste F, Illés $\mathrm{T}$ : The association of sagittal spinal and pelvic parameters in asymptomatic persons and patients with isthmic spondylolisthesis. J Spinal Disord Tech 15 : 24-30, 2002

24. Hanson DS, Bridwell KH, Rhee JM, Lenke LG : Correlation of pelvic incidence with low- and high-grade isthmic spondylolisthesis. Spine (Phila Pa 1976) 27 : 2026-2029, 2002 